\title{
Novel Variamine Blue Potentiometric Sensor
}

\author{
E. Khaled ${ }^{\#}$, M.A. El-Ries ${ }^{*}$, F.I. Zidane ${ }^{* *}$, S.A. Ibrahim* and \\ M.S. Abd-Elmonem* \\ Microanalysis Laboratory, National Research Centre, Giza, \\ *National Organization of Drug Control and Research and \\ ** Chemistry Department, Faculty of Science, Al-Azhar \\ University, Cairo, Egypt .
}

\begin{abstract}
T OVEL polyvinyl chloride (PVC) potentiometric sensors are 1 constructed for determination of variamine blue (VB). Different methods for electrode fabrication including; modification with the VBTPB ion pair, modification with sodium tetraphenylborate or soaking of the plain electrode in the ion-pair suspension, have been described. Electrode matrix compositions were optimized on the basis of effects of type and content of the modifier as well as influence of the plasticizers. The fabricated electrodes worked satisfactorily in the concentration range from $10^{-6}$ to $10^{-2} \mathrm{M}$ of VB. Electrodes modified with VB-TPB showed the best performance (Nernstian slope 62.0 0 .7 $\mathrm{mV}$ decade $^{-1}$ ) with fast response time of about $8 \mathrm{sec}$ and adequate lifetime ( 4 weeks). The developed electrodes have been successfully applied as end point indicator electrode for the potentiometric titration of $6.75-20.25 \mathrm{mg}$ VB with high accuracy and precision. The solubility products of different VB ion-pair were determined conductometrically.
\end{abstract}

Keywords: Variamine blue, PVC electrode fabrication, Potentiometric titration, Ion pairs and Solubility products.

4-Amino 4'-methoxydiphenylamine, known as Variamine Blue (VB) was first suggested as a redox indicator by Erdey ${ }^{(1,2)}$. This reagent is soluble in water and produces a colorless solution which turns blue violet meriquinone which absorbs at 570-610 $\mathrm{nm}$ upon oxidation ${ }^{(3)}$.

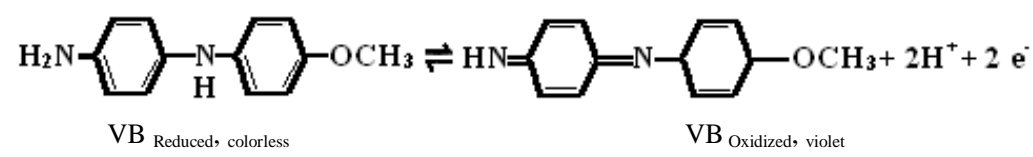

VB was recommended as redox indicator for potentiometric and visual titrations with $\mathrm{Fe}(\mathrm{III})^{(3,4)}$, bromamine- $\mathrm{B}^{(5)}$ or bromate ${ }^{(6)}$. More recently, Basavaiah and Charan used VB for the assay of methdilazine in bulk drug applying potassium iodate as oxidant ${ }^{(7)}$.

"E-mail address: elmorsykhaled@yahoo.com 
Heavy metals are important environmental pollutants, second only to pesticides in terms of environmental impact; therefore, monitoring of heavy metals at trace levels is usually an increasingly important issue. Simple, rapid and sensitive spectrophotometric methods utilizing VB as chromogenic reagent were suggested for determination of $\operatorname{arsenic}^{(8)}$, $\operatorname{chromium}^{(9)}$, $\operatorname{vanadium}^{(10)}$ or selenium $^{(11)}$. Because of the growing need for high sensitive analytical methods, the catalytic kinetic method has become an attractive procedure as the trace determination can be achieved without the use of expensive or special equipment with lower probability to receive interferences ${ }^{(12,13)}$. Catalytic methods are usually based on the oxidation of organic indicators with various oxidants. Among these organic indicators, VB was applied for catalytic spectrophotometeric determination of environmentally important species $^{(14-17)}$. Finally, the utility of $\mathrm{VB}$ as an analytical reagent has been well reviewed by Bishop ${ }^{(18)}$.

The yield of VB from an initial commercial manufacturing synthesis is approximately $75 \%$ and there may be significant variations between batches. However, relatively little information on the analysis of such dyestuffs has been published; but the book of Lastovskii and Vainshtein ${ }^{(19)}$ is still a very useful manual. Application of spectrophotometeric methods is not possible since there is no pure standard dye for construction of the calibration curve. On the other hand, chromatographic methods require expensive apparatus with special columns or involve several manipulation steps before the final result of analysis. In contrast, electrochemical techniques are of choice since they possess the advantages of simplicity, accuracy and low cost without separation or pretreatment procedures. Although ion- selective electrodes (ISEs) had found wide applications for dye analysis ${ }^{(20-24)}$, no VB sensor was found in literature.

The present study is concerned with preparation, characterization and application of simple potentiometric sensors for rapid determination of RB. Electrodes were fabricated in plain and modified forms and subjected to a series of tests to select sensor possessing the most favorable analytical characteristics. The developed sensors were also applied as indicator electrode in the potentiometric titration of VB.

\section{Experimental}

\section{Apparatus}

All potential measurements were performed using a 4310 Jenway digital $\mathrm{pH}$ meter with PC interface, equipped with silver-silver chloride double junction reference electrode in conjugation with the sensing dye ISE. A combined $\mathrm{pH}$ glass electrode was used for all $\mathrm{pH}$ measurements. Conductance was measured using 4310 Jenway Conductivity meter. Manual potentiometric titrations were performed using a Brand Digital Burette.

\section{Reagents}

All reagents were of the analytical grade and double distilled water was used throughout the experiments. Variamine Blue $\left(10^{-2} \mathrm{M}\right)$ stock solution was Egypt. J. Chem. 53, No. 4 (2010) 
prepared by dissolving the appropriate weight of the $\mathrm{VB}$. $\mathrm{HCl}\left(\mathrm{C}_{13} \mathrm{H}_{14} \mathrm{~N}_{2} \mathrm{O}-\mathrm{HCl}\right.$, $\mathrm{BDH}, \mathrm{UK}$ ) in hot water followed by filtration and complete the volume to $100 \mathrm{ml}$. o-Nitrophenyloctylether (o-NPOE) from Sigma was used for sensors fabrication. Other types of plasticizers, namely dibutylphthalate (DBP), dioctylphthalate (DOP), dioctylsebacate (DOS) and tricresylphosphate (TCP) were purchased from BDH, Sigma, AVOCADO and Fluka, respectively.

Sodium tetraphenylborate (NaTPB) solution (ca. $10^{-2} \mathrm{M}$ ) was prepared by dissolving a weighed amount of the substance (Fluka) in water, then adjusted to $\mathrm{pH} 9$ by adding sodium hydroxide solution and completed to the desired volume with water. The resulting solution was standardized potentiometrically against standard $10^{-2} \mathrm{M}$ thallium (I) nitrate solution ${ }^{(25)}$. Reineckate ammonium salt (RAS, Fluka), phosphotungstic acid (PTA, BDH), and phosphomolybdic acid (PMA, Fluka) were used for precipitation of different VB ion pairs.

\section{Electrode construction}

Ion pair preparation

Ion-pairs synthesis protocol included drop wise addition of $10^{-2} \mathrm{M}$ aqueous solution of ion pairing agents (NaTPB, RAS, PTA or PMA) to $50 \mathrm{ml}$ of $10^{-2} \mathrm{M}$ VB solution and the mixture was left to react for 5 min under stirring at room temperature. The resulting precipitate was then filtered off and left to dry for $24 \mathrm{hr}$ at $60^{\circ} \mathrm{C}$.

\section{Conductometric determination of the stoichiometric ratios}

A definite volume of $10^{-2} \mathrm{M}$ VB was transferred to a $50 \mathrm{ml}$ volumetric flask and made up to the mark with bidistilled water. The dye solution was placed in a suitable titrating vessel and the conductivity cell was immersed, then a titrant of $10^{-2} \mathrm{M}$ of TPB, RAS; $2.5 \times 10^{-3} \mathrm{M}$ of PMA, PTA was added from a digital burette and the conductance $(\mu \mathrm{S})$ was measured after 2 min to ensure the equilibrium. To eliminate the effect of dilution on conductance, the measured values were corrected for volume change by means of the following equation, assuming that conductivity is a linear function of dilution:

$$
\mathrm{k}_{\mathrm{corr}}=\mathrm{k}_{\mathrm{obs}}\left[\left(\mathrm{v}_{\mathrm{o}}+\mathrm{v}_{\mathrm{added}}\right) / \mathrm{v}_{\mathrm{o}}\right]
$$

where, $k_{o b s}$, the observed specific conductivity, $v_{o}$, the initial volume, and $v_{a d d e d}$, the added volume. The corrected conductivity was then plotted against the volume added of titrant and the first derivative was used to estimate the end point.

Conductometric determination of the solubility products

Series of solutions of different concentrations $\left(10^{-2}-10^{-4} \mathrm{M}\right)$ were prepared for each of VB, TPB, RAS, PMA or PTA. The conductivities of these solutions were measured at $25^{\circ} \mathrm{C}$ and the specific conductivities $(k)$, corrected for the effect of dilution, were calculated and used to obtain the equivalent conductivities $(\lambda)$ of these solutions.

$$
\lambda=1000 \mathrm{k} / \mathrm{C}
$$

Egypt. J. Chem. 53, No. 4 (2010) 
$\lambda$ (at a finite concentration) and $\lambda_{\mathrm{o}}$ (at infinite dilution) can be related by the equation $^{(26)}$ :

$$
\lambda=\lambda_{\mathrm{o}}-\left(\mathrm{a}+\mathrm{b} \lambda_{\mathrm{o}}\right) \mathrm{C}^{1 / 2}
$$

Straight line plots of $\lambda$ versus $C^{1 / 2}$, were constructed and the equivalent conductance values at infinite dilution $\left(\lambda_{\circ \mathrm{VB}}, \lambda_{\circ \mathrm{TPB}}, \lambda_{\circ \mathrm{RAS}}, \lambda_{\circ \mathrm{PMA}}\right.$ and $\left.\lambda_{\circ \mathrm{PTA}}\right)$ were determined from the intercept of the respective line with the $\lambda$ axis. The equivalent conductance values of the IPs under complete dissociation condition $\left(\lambda_{\text {IIP }}\right)$ were calculated from Kohlrausch's law of independent migration of the ions $^{(27,28)}$.

$$
\lambda_{\circ \mathrm{IP}}=\mathrm{n} \lambda_{\circ \mathrm{VB}}+\lambda_{\circ} \text { (ion pairing agent) }
$$

where; $n$ is the stoichiometric ratio.

The solubility $(S)$ and the solubility product $\left(K_{s p}\right)$ of a particular ion associate were calculated using the following equations:

$$
\mathrm{S}=\mathrm{k}_{\mathrm{s}} \times 1000 / \lambda_{\text {。IP }}
$$

$\mathrm{K}_{\mathrm{sp}}=\mathrm{S}^{2} \quad$ for 1: 1 ion associate

$\mathrm{K}_{\mathrm{sp}}=27 \mathrm{~S}^{4} \quad$ for $1: 3$ ion associate

where $k_{s}$, is the specific conductivity of a saturated solution of IP at $25^{\circ} \mathrm{C}$ and corrected for the effect of dilution.

\section{Electrode fabrication}

Matrices compositions composed of $7.5 \mathrm{mg}$ of VB-TPB or $30 \mathrm{mg}$ of NaTPB, were mixed with $240 \mathrm{mg}$ o-NPOE, $6 \mathrm{ml}$ THF and $240 \mathrm{mg}$ PVC. The cocktail was stirred for $5 \mathrm{~min}$ and poured into a Petri dish " $5 \mathrm{~cm}$ " diameter. After $24 \mathrm{hr}$ of slow evaporation of solvent, a master membrane with $0.11 \mathrm{~mm}$ thickness was obtained. One end of a PVC tube was softened by immersion in THF for $1 \mathrm{~min}$, a piece " $2 \mathrm{~cm}$ diameter disk" of the PVC membrane was mounted on the softened end of the PVC tubing with the help of adhesive solution prepared by dissolving PVC in THF. The PVC closed tube with the membrane was filled with $10^{-2} \mathrm{M}$ $\mathrm{KCl}$ and $10^{-2} \mathrm{M} \mathrm{VB}$ solution using $\mathrm{Ag} / \mathrm{AgCl}$ as internal reference electrode. The fabricated electrodes were soaked in $10^{-2} \mathrm{M}$ of $\mathrm{VB}$ for $24 \mathrm{hr}$ before using. The plain electrode was prepared in the same manner using the plain membrane (without any modification) where the electrode was soaked in the suspended solution of VB-TPB ion pair for $24 \mathrm{hr}$ before measurement.

\section{Analytical procedure}

Calibration of sensors

Sensors were calibrated by transferring $25 \mathrm{ml}$ aliquots of $10^{-7}-10^{-2} \mathrm{M} \mathrm{VB}$ solutions into a $50 \mathrm{ml}$ double jacket thermostated glass cell at $25^{\circ} \mathrm{C}$ followed by immersing the sensor in conjugation with $\mathrm{Ag} / \mathrm{AgCl}$ double junction reference electrode in the solution. The potential readings were recorded after stabilization Egypt. J. Chem. 53, No. 4 (2010) 
and plotted against dye concentration in logarithmic scale (-log [VB]) and the sensors performances were evaluated according to IUPAC recommendation ${ }^{(29)}$.

\section{Electrode response time}

The dynamic response time of the electrode was tested by measuring the time required to achieve a steady state potential (within $\pm 1 \mathrm{mV}$ ) after sudden 10-fold increase in VB concentration from $10^{-6}$ to $10^{-3} \mathrm{M}$.

\section{Effect of $p H$}

The influence of $\mathrm{pH}$ on the electrode response was checked by recording the potential readings of the cell for solutions containing $10^{-3} \mathrm{M} \mathrm{VB}$ at different $\mathrm{pH}$ values ( $\mathrm{pH} 2-6)$. Variation of $\mathrm{pH}$ value was done by adding very small volumes of $\mathrm{HCl}$ and/or $\mathrm{NaOH}$ solution $(0.1-1 \mathrm{M}$ of each) to the dye solution.

\section{Potentiometric titration}

Aliquots of the sample solution containing $6.75-20.25 \mathrm{mg} \mathrm{VB}$ was titrated with standardized NaTPB. The titration process was monitored using VB sensor in conjugation with $\mathrm{Ag} / \mathrm{AgCl}$ reference electrode where the emf values were plotted against the $\mathrm{ml}$ added from the titrant to estimate the end point.

\section{Results and Discussion}

\section{Preliminary IP identification studies}

$\mathrm{VB}$ is a tertiary amine azo dye which forms water insoluble ion- pair complexes with the oppositely charged anions such as TPB, RAS, PTA or PMA. The resultant IPs can be used as ion exchangers for VB potentiometric sensors. From this point of view, different types of VB-IPs were prepared and their stoichiometric ratios were estimated from elemental analysis and conductometric titration data. The elemental analysis data (Table 1) revealed that VB forms 1:1 IPs with both TPB and RAS while PTA and PMA showed ratio 1:3.

TABLE 1. Characterization of different VB-IPs.

\begin{tabular}{|l|c|c|c|c|c|c|c|c|c|c|}
\hline \multirow{2}{*}{ IP } & \multirow{2}{*}{$\mathbf{M W t}_{\text {cal }}$} & \multicolumn{2}{|c|}{ C\% } & \multicolumn{2}{c|}{ H\% } & \multicolumn{2}{c|}{ N\% } & \multicolumn{2}{c|}{ S\% } & \multirow{2}{*}{ Tentative Formula } \\
\cline { 3 - 11 } & & Calc. & Found & Calc. & Found & Calc. & Found & Calc. & Found & \\
\hline VB-TPB & 543.8 & 81.6 & 80.8 & 5.7 & 5.8 & 7.7 & 7.9 & - & & {$\left[\mathrm{C}_{13} \mathrm{H}_{14} \mathrm{~N}_{2} \mathrm{O}\right]\left[\mathrm{C}_{24} \mathrm{H}_{20} \mathrm{~B}\right]$} \\
\hline VB-Rn & 543 & 37.6 & 37.2 & 3.1 & 3.0 & 23.2 & 23.2 & 23.6 & 23.2 & {$\left[\mathrm{C}_{13} \mathrm{H}_{14} \mathrm{~N}_{2} \mathrm{O}_{[}\left[\mathrm{C}_{4} \mathrm{H}_{6} \mathrm{CrN}_{6} \mathrm{~S}_{4}\right]\right.$} \\
\hline VB-PMA & 2497 & 18.7 & 18.1 & 0.6 & 0.7 & 5.4 & 5.1 & - & & {$\left[\mathrm{C}_{13} \mathrm{H}_{14} \mathrm{~N}_{2} \mathrm{O}_{3}\left[\mathrm{PMo}_{12} \mathrm{O}_{40}\right]\right.$} \\
\hline VB-PTA & 3552 & 13.2 & 13.1 & 0.4 & 0.2 & 3.5 & 3.6 & - & & {$\left[\mathrm{C}_{13} \mathrm{H}_{14} \mathrm{~N}_{2} \mathrm{O}_{3}\left[\mathrm{PW}_{12} \mathrm{O}_{40}\right]\right.$} \\
\hline
\end{tabular}

The stoichiometric ratios of the IPs formed can be estimated from the conductometric titration curve obtained by plotting the change in conductance versus volume of titrant added (Fig. 1). By addition of the titrant to VB solution, the system showed a regular rise in conductance up to the equivalence point where a sudden change in the conductance was observed. Intersect of the two straight lines determine the stoichiometric ratio of the complexes formed. The obtained results sustained the elemental analysis data for the complex formation ratios. 

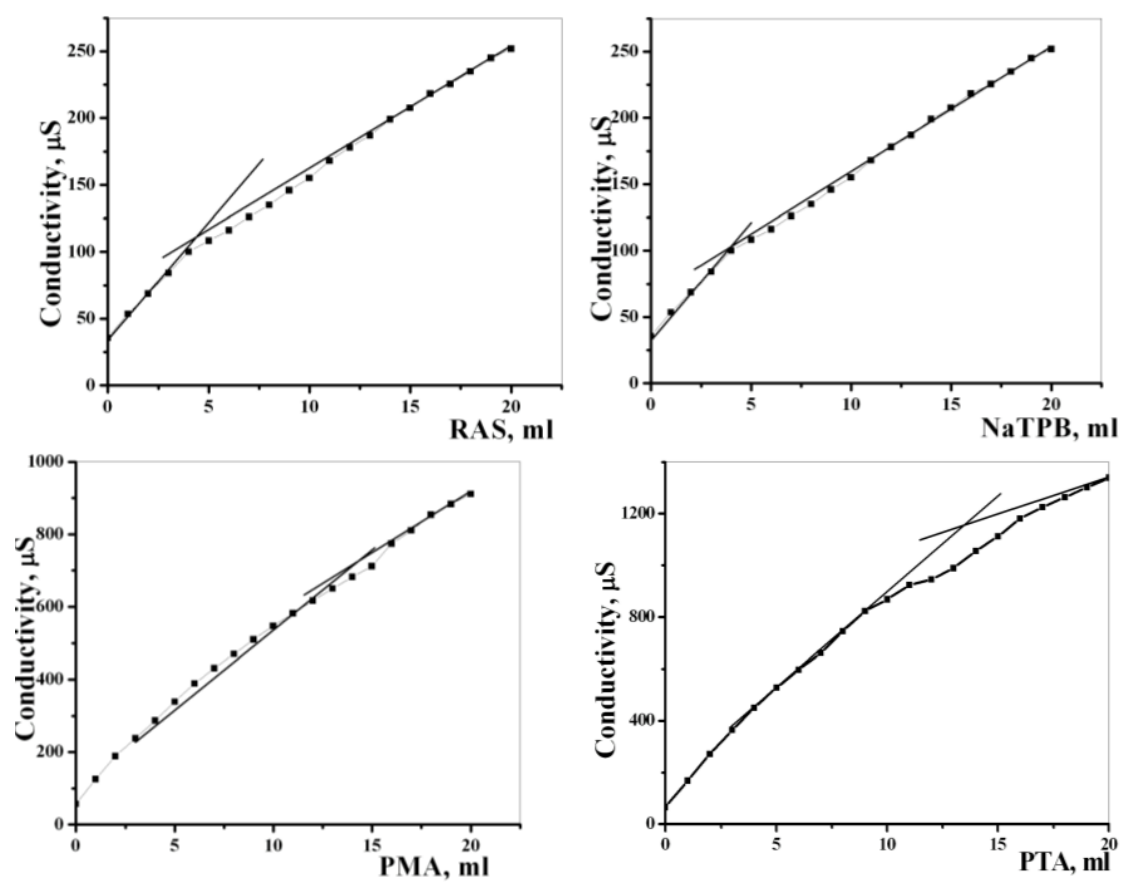

Fig. 1. Conductometric titration of VB with different ion pairing agents.

The solubility products of the ion associates were determined conductimetrically and found to be $5.74 \times 10^{-7}, 1.72 \times 10^{-8}, 1.89 \times 10^{-10}$ and $1.11 \times 10^{-11}$, for VB-TPB, VB-RAS, VB-PTA and VB-PMA, respectively.

Optimization of the electrode performance

For quantitative and qualitative composition optimization of the developed PVC sensors, an election scheme was followed. Both unmodified (plain) and modified electrodes (either with the VB-IPs, or the ion pairing agents) were prepared and tested for nature and content of modifier, plasticizer, $\mathrm{pH}$, response time and applications.

Electrodes modified with VB- ion pairs

The customary type of ion selective electrode is one in which the membrane is composed of a water-immiscible organic solvent containing the ion in question, usually in the form of an ion-pair with some anionic ion pairing agents such as NaTPB, TPA, TSA, flavianate, reinickate or PMA in the electrode matrixes $^{30-33}$. Different VB-IPs were incorporated in the PVC matrix, and the fabricated electrodes were conditioned in $10^{-2} \mathrm{M}$ of $\mathrm{VB}$ solution for $24 \mathrm{hr}$. Preliminary experiment declared that PVC electrodes contain no electroactive material and plasticized with o-NPOE showed no response towards the VB; while those incorporated with different VB-IPs gave Nernstian responses with slopes and sensitivities depend on the nature of ion pair used. The electrode Egypt. J. Chem. 53, No. 4 (2010) 
incorporated with VB-TPB ion pair showed the best performance (slope 51.5 \pm 2.8 $\mathrm{mV}$ decade $^{-1}$ ) compared to electrodes modified with other VB ion pairs. This behavior may be attributed to the poor solubility of these ion pairs in the membrane matrix.

Furthermore, the amount of the electroactive material in the electrode matrix should be sufficient to achieve reasonable ionic exchange and chemical equilibrium at the membrane/solution interface that is responsible for the electrode potential. If such material is present in excess, over saturation occurs in the membrane network, hindering the ionic exchange process and leading to unsatisfactory performance. Thus, the influence of the VB-TPB content in the PVC matrix was investigated by varying the IP content in the electrode matrix from 1 to $10 \mathrm{mg}$ (Fig. 2). Addition of $7.5 \mathrm{mg} \mathrm{VB-TPB}$ to the membrane matrix was sufficient for the ionic exchange at membrane interface; the corresponding slope was $56.3 \pm 2.4 \mathrm{mV} /$ decade in the tested concentration range (from $10^{-6}$ to $\left.10^{-2} \mathrm{M}\right)$, above this value the slope of the electrode decreased to reach 48.0 $\mathrm{mV} /$ decade with $10 \mathrm{mg}$ IP.

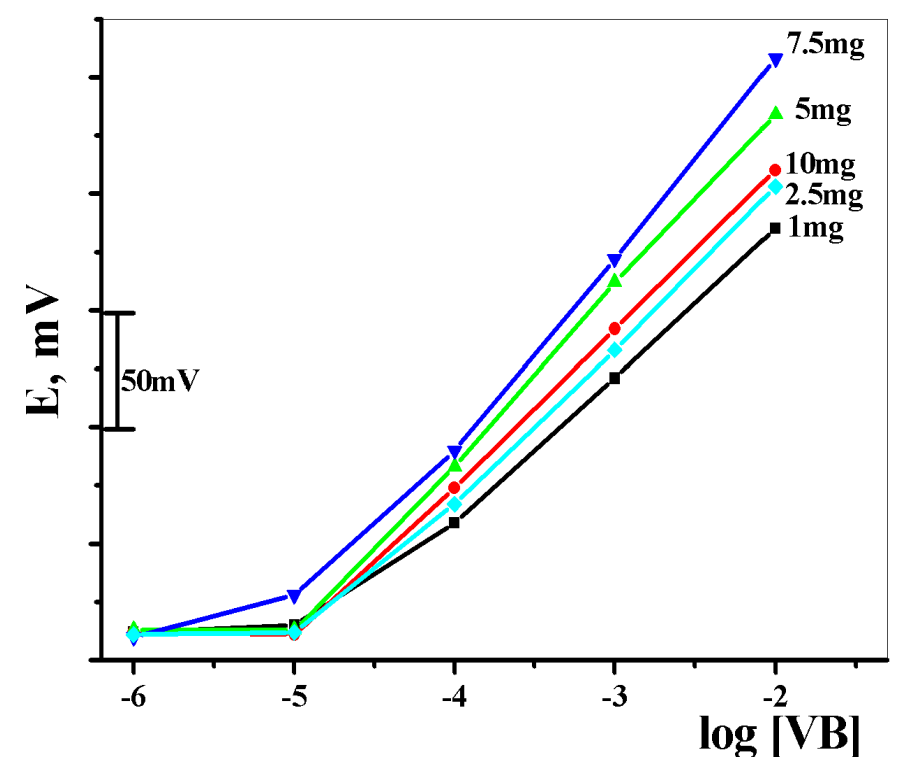

Fig. 2. Effect of the VB-TPB IP content on electrode performance.

Electrode modified with the ion pairing agents (In situ)

Incorporation of a suitable ion pairing agent in the electrode matrix followed by soaking in the dye solution may lead to the formation of an ion exchanger at the electrode surface which subsequently extracted by the plasticizer into the electrode bulk. Such technique will reduce the time required for the electrode fabrication as there is no need for IP precipitation.

Egypt. J. Chem. 53, No. 4 (2010) 
The effect of the ion pairing agent nature on the electrode performance was tested as the electrode matrices containing different ion pairing agents (NaTPB, RAS, PTA and PMA) were prepared and presoaked in $10^{-2} \mathrm{M} \mathrm{VB}$ solution for $24 \mathrm{hr}$. The obtained results indicated the priority of the incorporation of NaTPB indicated by the highest slope $\left(60 \pm 1.3 \mathrm{mV}\right.$ decade $\left.^{-1}\right)$ compared to other ion pairing agents that gave relative lower slopes (Fig. 3); which may be explained from the point of view of the difference in the extraction of the formed ion-pairs into the electrode matrices. The content of Na-TPB within the electrode matrices was varied from 10 to $50 \mathrm{mg}$ and incorporation of $30 \mathrm{mg}$ of Na-TPB gave the highest slope $\left(64.6 \pm 1.1 \mathrm{mV}\right.$ decade $\left.^{-1}\right)$.
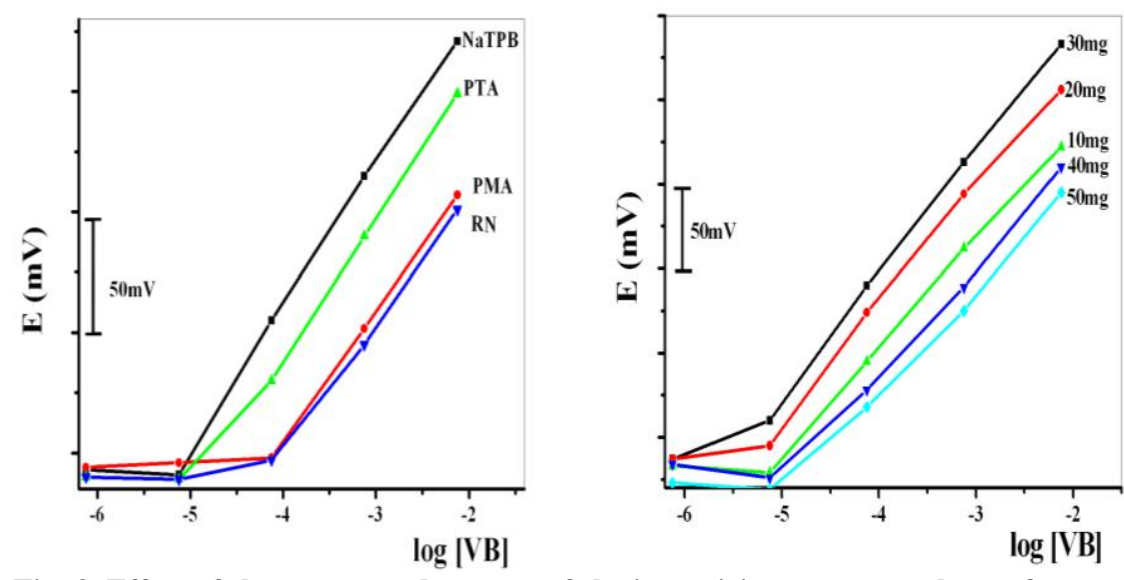

Fig. 3. Effect of the nature and content of the ion pairing agents on the performance of VB-PVC electrodes.

Soaked electrodes

In addition to the aforementioned methods for the electrode fabrication, a simple and reliable suggested procedure could be applied by soaking the plain electrodes (fabricated without any modification) in the aqueous suspension of the lipophilic VB-IPs solutions. The electrode mediator (plasticizer) extracts IPs and becomes gradually saturated with this IP and hence, there is no need to incorporate neither the IPs nor the ion pairing agents into the electrode matrix. The IP concentration in the organic phase increases with increasing both the extractability and the solubility product of the IP formed ${ }^{(34,35)}$.

Calibration graphs of electrodes soaked in different VB ion pair suspensions showed that the electrodes soaked in the VB-TPB had the best sensitivity indicated by the highest slope $\left(57.9 \pm 2.8 \mathrm{mV}\right.$ decade $\left.{ }^{-1}\right)$ when compared with other IPs which may be directly related to the solubility products and extraction of the different ion-pairs in the membrane plasticizer.

Egypt. J. Chem. 53, No. 4 (2010) 


\section{Effect of membrane plasticizer}

Plasticizers play an important role in the behavior of ISEs since they improve the solubility of the sensing material and lower the overall bulk resistance of the electrode due to their polarity characteristics ${ }^{(36,37)}$.

The effect of membrane plasticizer on the electrode performance has been studied. The electrode plasticized with $o$-NPOE was compared with those plasticized with TCP, DOS, DOP and DBP. The obtained calibration graphs (Fig. 4) clarified that the membrane plasticized with $o$-NPOE showed the highest sensitivity indicated by the highest slope values, which may be related to its high dielectric constant $(\varepsilon=24,17.6,3.88,5.2$ and 4.7 for the tested plasticizers in the same order).

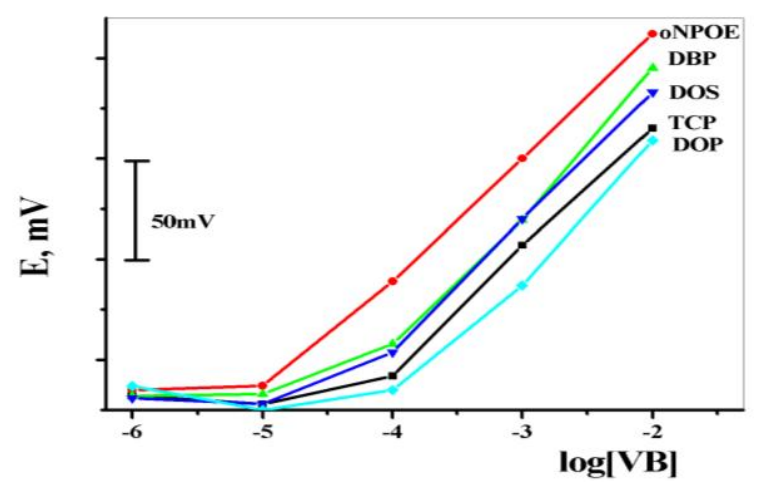

Fig. 4. Effect of the plasticizer on the performance of soaked VB electrodes.

\section{Sensors performance}

The potentiometric response characteristics of different VB-PVC sensors prepared with different methods (modification with VB-TPB ion pair, modification with NaTPB or plain) were evaluated according to IUPAC recommendations ${ }^{(27)}$. Data obtained (Table 2) indicated that the developed sensors can be successfully applied for the potentiometric determination of VB in the concentration range from $10^{-6}$ to $10^{-2} \mathrm{M}$ with Nernstian cationic slopes depend on the method of fabrication. The electrodes modified with NaTPB showed relatively higher slope $\left(64.6 \pm 1.1 \mathrm{mV}\right.$ decade $\left.^{-1}\right)$ compared with those modified with VB-TPB ion-pair or plain electrodes. The limit of detection varies with the electrode type as it reached $4.6 \times 10^{-7} \mathrm{M}$ with the VB-TPB modified electrode. 
TABLE 2. Performance characteristics* of VB sensors fabricated with different techniques.

\begin{tabular}{|l|c|c|c|}
\hline \multicolumn{1}{|c|}{ Sensor } & $\begin{array}{c}\text { Modified with VB- } \\
\text { TPB }\end{array}$ & $\begin{array}{c}\text { Modified with } \\
\text { NaTPB }\end{array}$ & Soaked \\
\hline Concentration range (M) & $10^{-6}-10^{-2}$ & $10^{-5}-10^{-2}$ & $10^{-5}-10^{-2}$ \\
\hline Intercept (mV) & $193.2 \pm 3.3$ & $159.0 \pm 5.2$ & $264.7 \pm 3.8$ \\
\hline Slope (mV/ decade) & $62.0 \pm 0.7$ & $64.6 \pm 1.1$ & $54.8 \pm 1.2$ \\
\hline r & 0.9945 & 0.9994 & 0.9993 \\
\hline LOD (M) & $4.6 \times 10^{-7}$ & $5.2 \times 10^{-6}$ & $2.5 \times 10^{-6}$ \\
\hline Response time (s) & 8 & 12 & 8 \\
\hline Lifetime (day) & 28 & 21 & 14 \\
\hline pH range & $3-5$ & $3-5$ & $3-5$ \\
\hline
\end{tabular}

*Average of five calibration graphs

For analytical applications, the response time of a new fabricated sensor was of critical importance. The response times of the fabricated electrodes were measured according to IUPAC recommendation. The average response time is defined as the time required for the electrode to reach a stable potential (within $\pm 1 \mathrm{mV}$ of the final equilibrium value) after sudden 10 -fold increase in concentration by addition of small increments of $10^{-2} \mathrm{M} V \mathrm{VB}$ solution. For the modified and soaked electrodes, the response time was found to be $8 \mathrm{~s}$ for concentration of $\geq 1 \times 10^{-4} \mathrm{M}$ and $10 \mathrm{~s}$ for lower concentrations while that modified with NaTPB showed longer response time of 12 and $14 \mathrm{~s}$, respectively.

The useful lifetimes of different fabricated electrodes were tested by performing day-to-day calibrations; the fabricated electrodes showed useful lifetime of about 4 weeks during which the Nernstian slopes did not change significantly $\left( \pm 2 \mathrm{mV}\right.$ decade $\left.^{-1}\right)$.

The influence of $\mathrm{pH}$ on the electrode potential was studied by measuring the calibration graphs at different $\mathrm{pH}$ values (from 2 to 6) as higher $\mathrm{pH}$ values cause precipitation of the VB base with sharp decrease in the electrode potential. The electrode showed a stable potential reading in the $\mathrm{pH}$ range from 3 to 5 .

The selectivity of the prepared VB sensors was tested towards different interfering ions using Separate Solution Method (SSM). The potential of the cell comprising an $\mathrm{VB}$ and a $\mathrm{RE}$ is measured with two separate solutions, one containing the ion $102-M V B$, the other one containing the $10-2 \mathrm{M}$ the interfering ion. If the measured values are $E_{\mathrm{A}}$ and $E_{\mathrm{B}}$, respectively, the value of is calculated from the equation:

$$
\log K_{A, B}=\left[\left(E_{B}-E_{A}\right) z_{A} F / R T \ln 10\right]+\left(1-z_{A} / z_{B}\right) \log a_{A}
$$

which is equivalent to:

$$
K_{A, B}=a_{A}^{\left(1-z_{A} / z_{B}\right)} e_{B}^{\left(E_{B}-E_{A}\right) z_{A} F /(R T)}
$$

Egypt. J. Chem. 53, No. 4 (2010) 
The developed sensors were highly selective; organic compounds (glycine, caffeine, citrate, maltose, sucrose, and starch) as well as inorganic cations $\left(\mathrm{Na}^{+}\right.$, $\mathrm{K}^{+}, \mathrm{Li}^{+}, \mathrm{Ca}^{2+}, \mathrm{Mg}^{2+}$, and $\mathrm{NH}_{4}^{+}$) did not show significant interference.

\section{Potentiometric titration}

In contrast to direct potentiometric measurements requiring careful calibrations of measuring cells, the potentiometric titration techniques offer the advantage of high accuracy and precision; although the cost of increased time and consumption of reagents used as titrants. In the potentiometric titration of VB, different titrants and electrodes were investigated. Application of NaTPB as titrant gave the best titration curve with the highest potential break at the end point and a well defined reaction sticiochiometry (1:1) while other titrants (PTA, PMA) gave a poor titration curves.

When ISEs are used to monitor titration based on IP formation, the magnitude of both potential break and sharpness at the inflexion point of the titration curve is predetermined by the solubility of the corresponding IP in membrane plasticizer and also related to the extractability of the IP into the membrane mediator $^{(20,21,25,34-36)}$. The influence of the membrane plasticizer on the titration performance was investigated by performing the titration using electrodes plasticized with different plasticizer namely $o$-NPOE, TCP, DOP or DOS. Generally, the electrodes plasticized with $o$-NPOE gave the highest total potential change $(\triangle \mathrm{E}=200 \mathrm{mV})$ compared with those plasticized with TCP, DOP or DOS ( $\triangle \mathrm{E}$ were 150,140 and $120 \mathrm{mV}$ for the plasticizers in the same order) which can be explained by higher extractability of the VB-TPB ion pairs into the membrane plasticizer due to the relative higher dielectric constant of $o$-NPOE.

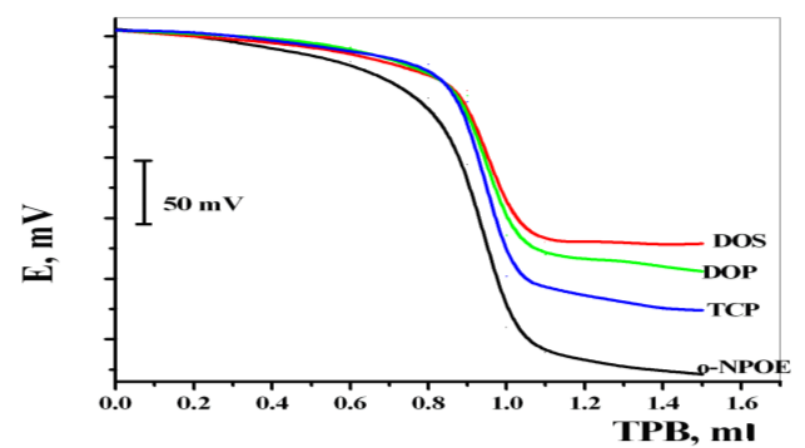

Fig. 5. Effect of the electrode plasticizer on the potentiometric titration of VB with NaTPB.

The effect of the electrode fabrication method on the titration process was also investigated. The plain electrodes showed the best titration curve compared with the modified with either the VB-TPB ion-pair or with the ion-pairing agent regarding the total potential change and the potential break at the end point. 
Under the optimum conditions, the titration curves were symmetrical in the concentration range $6.75-20.25 \mathrm{mg}$ VB with a very well defined potential jump indicating the high sensitivity of the electrode (Fig. 6).

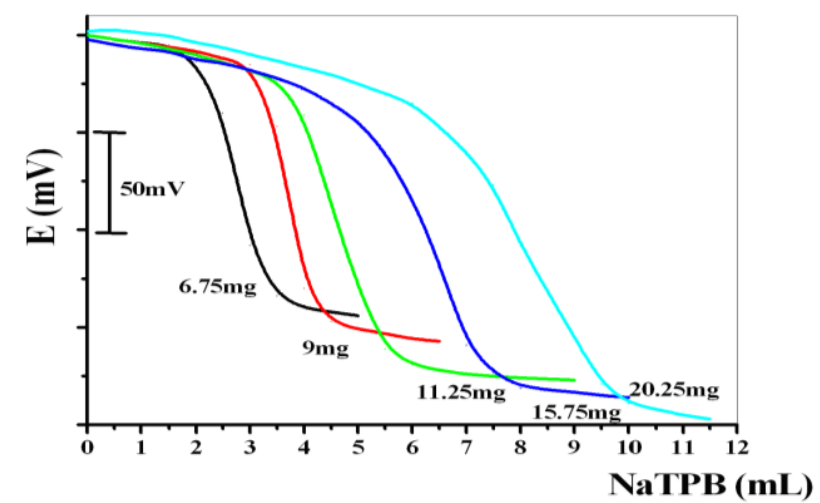

Fig. 6. Potentiometric titration of VB with $10^{-2} \mathrm{M}$ NaTPB using PVC electrode modified with VB-TPB.

Analytical application

The proposed electrode was successfully employed for the assay of VB applying potentiometric titration method. The data given (Table 3) clearly indicated satisfactory agreement between the VB contents in different samples determined by the proposed sensor and elemental analysis method as there is no official methods for VB.

\section{Conclusion}

The present work has successfully demonstrated the fabrication of novel VBPVC electrodes utilizing different preparation methods as no electrodes have been published for potentiometric determination of VB. The fabricated electrodes showed Nernstian slopes in the concentration range from $10^{-6}$ to $10^{-2} \mathrm{M}$ with fast response time $(8 \mathrm{~s})$ and long operational lifetime. The fabricated electrodes were successfully applied as end point indicator electrode for potentiometric titration of VB with NaTPB offering good accuracy and sensitivity. It should be mentioned that the fabricated electrodes were suitable in kinetic catalytic determination of trace iodide based on the oxidation of VB with hydrogen peroxide due to their high sensitivity and fast response to the change in VB concentration.

Egypt. J. Chem. 53, No. 4 (2010) 


\section{References}

1. Erdey, L. and Bodor, E., A new oxidation-reduction indicator: 4-amino-4'methoxydiphenylamine (Variamine Blue). Fresenius' Z. Anal. Chemie, 137, 410 (1953).

2. Erdey, L., Variamine Blue: a versatile redox indicator. Chemist-Analyst, 48, 106 (1959).

3. Erdey, L., Variamine Blue as a colorimetric reagent, Fresenius' Z. Anal. Chemie, 155, 90 (1957).

4. Noriyuki, N. and Motoharu, T., Theory of complexometric titrations with redox indicators. EDTA titration of $\mathrm{Fe}(\mathrm{III})$ using Variamine Blue as indicator. Anal. Chim. Acta, 36, 422 (1966).

5. Gowda, H.S. and Khan, H.N.A., Potentiometric and visual titrations with bromamineB. Talanta, 29, 787 (1982).

6. Gowda, H.S. and Gurumurthy, S., Analytical applications of bromamine-T. Indian $J$. Chem. A 21, 550 (1982).

7. Basavaiah, K. and Charan, V.S., Four simple procedures for the assay of methdilazine in bulk drug and in tablets and syrup using potassium iodate. II Farmaco, 58, 285 (2003).

8. Narayana, B., Cherian, T., Mathew, M. and Pasha, C., Spectrophotometric determination of arsenic in environmental and biological samples. Indian J. Chem. Tech. 13, 36 (2006).

9. Narayana, B. and Cherian, T., Rapid spectrophotometric determination of trace amounts of chromium using variamine blue as a chromogenic reagent. J. Brazilian Chem. Soc. 16, 888 (2005).

10. Kumar, T. N. and Kiran, R., Spectrophotometric determination of vanadium using variamine blue and its application to synthetic, environmental and biological samples. J. Iranian Chem. Soc. 2, 161 (2005).

11. Hosakere, R.D. and Kiran, K.T.N., A facile spectrophotometric method for the determination of selenium. Anal. Sci. 17, 1309 (2001).

12. Mottola, H.A. and Perez-Bendito, D., Kinetic determinations and some kinetic aspects of analytical chemistry. Anal.Chem. 66, 131R (1994).

13. Prez Bendito, D. and Silva, M., Kinetic Methods in Analytical Chemistry, Ellis Horwood, Chichester, England (1988).

14. Bilenko, O.A. and Mushtakova, S.P., New catalytic methods for determination of iridium (IV). Zh. Anal. Khim. 31, 52 (1971). 
15. Kawashima, T., Hatakeyama, N. and Kamada, M., Spectrophotometric determination of ultratrace amounts of iron by its catalytic effect. Nippon Kagaku Kaishi, 1, 84 (1981).

16. Shigenori, N., Kazuhiro, K. and Takuji, K., A new method for the determination of copper (II) by the catalytic oxidation of variamine blue B base analog. Chem. Lett. 7, 849 (1980).

17.Themelis, G.D., Trellopoulos, A.V., Tzanavaras, P.D. and Sofoniou, M., Highly selective flow injection spectrophotometric determination of gold based on its catalytic effect on the oxidation of variamine blue by potassium iodate in aqueous $\mathrm{N}, \mathrm{N}$-dimethylformamide medium. Talanta, 72, 277 (2007).

18. Bishop, E., Indicators, Pergamon Press Ltd., Oxford, Inc., New York, p. 395 (1972).

19. Lastovskii, R.P. and Vainshtein, Y., Tekhnicheskii analiz v proizvodstve promezhutochnykh produktov $i$ krasitelei, $3^{\text {rd }}$ ed., Goskhimizdat, Moscow (1958).

20.Vytřas, K., Ion-selective electrode potentiometry in control of dyestuffs production. Sel. Electrode Rev. 11, 111 (1989).

21.Vytřas, K. and Dajková, M., Coated-wire organic ion-selective electrodes in titrations based on ion-pair formation: Part 3. Determination of cationic triarylmethane dyestuffs. Anal. Chim. Acta, 141, 377 (1982).

22. Khaled, E., Vytras, K., Hassan, H.N.A. and Barsoum, B.N., Construction of Some new simple malachite green ion selective electrodes. Sci. Papers Univ. Pardubice, Ser A, 7, 33 (2001).

23.Wen, M.L., Zhao, Y.B., Chen, X. and Wang, C.Y., Potentiometric sensor for methylene blue based on methylene blue-silicotungstate ion association and its pharmaceutical applications. J. Pharm. Biomed. Anal. 18, 957 (1999).

24.Khaled, E., El-Ries, M.A., Zidane, F.I., Ibrahim, S.A. and Abd-Elmonem, M.S., Potentiometric determination of methylene blue in pharmaceutical preparation using simple PVC electrode. Anal. Chem. An Indian J., 9, 334 (2010).

25.Vytras, K., Potentiometric titrations based on ion-pair formation. Ion Sel. Electrode. Rev. 7, 77 (1985).

26.Scholz, F., Electroanalytical Methods, $2^{\text {nd }}$ ed., Springer-Verlag Berlin Heidelberg, (2010).

27.Issa, Y.M., Abdel-Ghani, N.T., Shoukry, A.F. and Ahmed, H.M., New conventional coated-wire ion-selective electrodes for flow-injection potentiometric determination of chlordiazepoxide. Anal. Sci. 21, 1037 (2005).

28.Rizk, M.S., Abdel-Ghani, N.T. and El-Nashar, R.M., Construction and performance characteristics of terbutaline plastic membrane electrode in batch and FIA conditions. Microchem. J. 70, 93 (2001).

Egypt. J. Chem. 53, No. 4 (2010) 
29.Buck, R.P. and Lindner, E., Recommendations for nomenclature of ion selective electrodes; IUPAC recommendations. Pure Appl. Chem. 66, 2527 (1994).

30.Vytras, K., The use of ion-selective electrodes in the determination of drug substances. J. Pharm. Biomed. Anal. 7, 789 (1989).

31.Cosofret, V.V. and Buck, R.P., Pharmaceutical Applications of Membrane Sensors, CRC Press, Boca Raton, FL (1992).

32.Katsu, T. and Watanabe, K., Determination of drug substances using ion selective electrodes. Jpn. J. Toxicol. Environ. Health, 42, 453 (1996).

33. Stefan, R.I., Baiulescu, G.E. and Aboul-Enein, H.Y., Ion-selective membrane electrodes in pharmaceutical analysis. Crit. Rev. Anal. Chem. 27, 307 (1997).

34. Vytras, K., Capoun, T., Halamek, E., Soucek, J. and Stajerova, B., Potentiometric ion-pair formation titrations of $\mathrm{N}$-alkyl-N-ethylpyrrolidinium cations using plastic membrane electrodes. Collect. Czech. Chem. Commun. 55, 941 (1990).

35. Vytras, K., Kalous, J. and Jezkova, J., Automated potentiometry as an ecologic alterative to two-phase titration of surfactants. Egypt. J. Anal. Chem. 6, 107 (1997)

36. Vytras, K., Kaderabkova, M. and Socha, J., Testing of some nitro compounds as new plasticizers of polymeric membrane-based electrodes. Sci. Pap. Univ. Pardubice, $\operatorname{Ser} A, \mathbf{3}, 323$ (1997).

37. George, W., Hand Book of Plasticizers, Chem. Tech. Publishing, Toronto, Ontario M1E 1C6, Canada (2004).

(Received 12/8/2010

Aceepted 4/10/2010) 


\section{أقطاب جهدية جديدة لازرق الفاريامين}

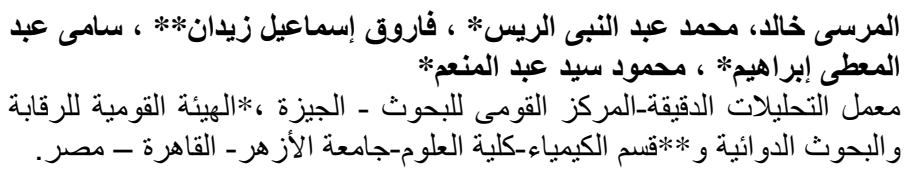

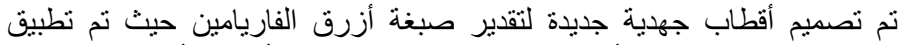

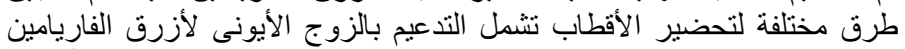

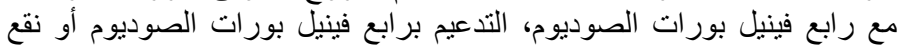

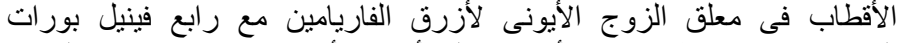

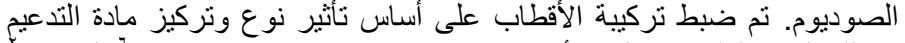

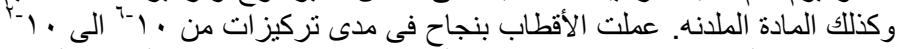

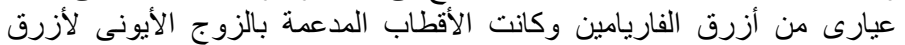

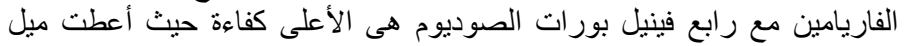

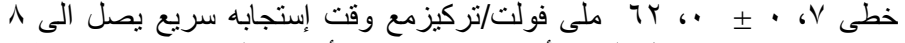

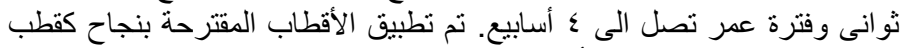

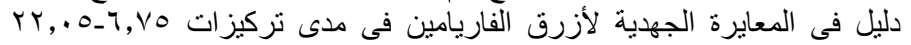

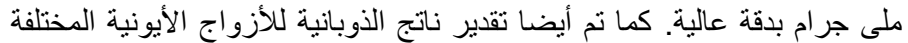
بطرق توصيلية. 